ORIGINAL ARTICLE

\title{
Cycle helmet ownership and use; a cluster randomised controlled trial in primary school children in deprived areas
}

\author{
D Kendrick, S Royal, on behalf of the "Lids for Kids" project team
}

Arch Dis Child 2004;89:330-335. doi: 10.1136/adc.2003.032052

See end of article for authors' affiliations

Correspondence to: Dr D Kendrick, Division of General Practice, University Park,

Nottingham NG'7 2RD,

UK; denise.kendrick@ nottingham.ac.uk

Accepted 25 July 2003

\begin{abstract}
Aims: To assess the effectiveness of two different educational interventions plus free cycle helmets, in increasing cycle helmet ownership and use.

Methods: A cluster randomised controlled trial was carried out in 28 primary schools in deprived areas of Nottingham, involving 1213 year 5 schoolchildren (age 9 and 10). Children received either a helmet + educational pack (educational pack and order form for free cycle helmet) or a helmet + multifaceted intervention (educational pack, order form for free cycle helmet, school assembly, lesson devoted to cycle helmet education, and an invitation to a school based cycling event).

Results: The helmet + educational pack was as effective as the helmet + multifaceted intervention in terms of helmet ownership (OR $1.51,95 \% \mathrm{Cl} 0.50$ to 4.58 ) and wearing (OR $0.98,95 \% \mathrm{Cl} 0.57$ to 1.68). Helmet ownership significantly increased from baseline with both interventions, and wearing significantly increased from baseline with the helmet + educational pack. The interventions reduced the inequality in helmet ownership between children residing in deprived and non-deprived areas that had been present prior to the study.

Conclusions: An educational pack plus a form to order a free cycle helmet is an effective way of increasing bicycle helmet ownership and use and reduces inequalities in helmet ownership among children in deprived areas. Further work is needed to determine the length of the effect of such interventions.
\end{abstract}

$\mathrm{B}$ icycle helmets afford protection against head and brain injuries to wearers of all ages involved in all types of crash, whether or not another vehicle is involved. ${ }^{1}$ Although childhood cycle injuries appear to be reducing in incidence, ${ }^{2}$ there were still more than 7500 children under 16 admitted to NHS hospitals between 1991 and 1995 with bicycle related head injuries. $^{3}$

There is a steep social class gradient in mortality from pedal cycle injury, with children from social class $\mathrm{V}$ having a mortality rate four times higher than children from social class I. ${ }^{4}$ Hospital admission rates for cycling injuries are $61 \%$ higher among children from deprived than affluent areas. We have recently shown that fewer children in deprived areas own cycle helmets than in affluent areas, but that once a child owns a helmet, helmet wearing is not related to deprivation. ${ }^{6}$ Previous work suggests the cost of a helmet can act as a barrier to its purchase, ${ }^{7}$ and cycle helmet subsidies have been shown to be effective in increasing helmet use among children in low income areas in the USA. ${ }^{8}$

At present there are relatively few randomised controlled trials of interventions to promote helmet use in children without enacting legislation. ${ }^{9-15}$ Four of the trials examined the effectiveness of physician counselling. Two of these found no effect on helmet ownership, ${ }^{9}{ }^{10}$ one found counselling plus a helmet discount coupon increased helmet purchase, ${ }^{12}$ and the fourth found counselling increased self reported helmet wearing. ${ }^{15}$ A further trial assessed the effect of co-payments for helmets in addition to physician counselling and found co-payments increased self reported helmet wearing as effectively as providing free helmets. ${ }^{14} \mathrm{~A}$ school based trial found that subsidised helmets increased observed helmet wearing rates and that education without subsidised helmets had no effect. ${ }^{11}$ Finally a trial of a school based bicycle skills training programme found no effect on self reported helmet use. $^{13}$ More non-randomised studies exist, ${ }^{86-25}$ many of which used complex multifaceted interventions. At present it is not clear whether some elements of these interventions are more effective than others, and if so, which elements this applies to. Several studies have also assessed the effect of the interventions by social group, finding conflicting results. ${ }^{78181924}$ There is therefore a need to determine which elements of a cycle helmet programme are effective, and whether such programmes are equally effective in children from different social groups. This information is important to ensure effective use of resources for injury prevention and the reduction of health inequalities.

The objectives of this study were therefore to evaluate the effectiveness of two different educational interventions in addition to free cycle helmets in increasing cycle helmet ownership and wearing among 9 and 10 year olds from deprived areas of Nottingham, and to examine whether the effect differed by social group.

\section{METHODS}

All year 5 children registered at participating schools were eligible to take part in the study. All 120 primary schools in deprived areas in Nottingham (defined as a ward with a Townsend score $>0$ ) were invited to participate. Twenty nine schools participated in the study, and a further school acted as a pilot for the baseline data collection and interventions.

\section{Interventions}

The study compared two different educational interventions. Intervention l comprised an educational pack plus a form to order a free cycle helmet. Intervention 2 comprised an educational pack, a form to order a free helmet, an assembly, one lesson devoted to cycle helmet education, and an invitation to a cycling event. The educational pack included a road safety quiz, two educational booklets, a cycling fact sheet produced by Nottingham City Council Road Safety and Environmental Services Department, a helmet order form for the child to choose from five helmet designs, and a covering letter encouraging parent participation. Children were asked 
to complete the quiz with their parents and return it to the school with the helmet order form. Helmets were delivered to the schools direct from the manufacturer with written instructions on how to fit the helmet. The assembly, undertaken by a local doctor included an explanation of the effect of a head injury on a child's life, a video of a local child with a head injury, and an egg drop with and without a helmet. The objectives of the cycle helmet lesson were to increase understanding of how an injury affects the brain and its functioning, the need for protection of the brain when engaging in risky activity, and the impact a head injury can have on the life of a child and their family. Teachers were provided with a lesson plan, the Bicycle Helmet Initiative Trust video Happy Birthday Paul with a list of questions and answers to lead discussion after the video, and a human skull. All children were invited to a cycling event at a local school where cycle control skills were demonstrated and children had the opportunity to try activities aimed at increasing their control over their bike. The interventions took place in June and July 2001.

The interventions were designed based on the findings from three focus groups held with local children aged 11-12 who had taken part in a cycle helmet project the previous year, and from a review of the literature, and was informed by advice from teachers, health promotion specialists, school nurses, road safety officers, the British Cycling Federation, paediatricians, accident and emergency department consultants, and general practitioners. It was piloted in one school not taking part in the project.

\section{Outcomes}

The primary outcomes for the study were the proportion of children owning and wearing a cycle helmet. These were assessed by anonymous self completion questionnaire, based on questions used in previous cycle helmet research, ${ }^{26}{ }^{27}$ using two cross-sectional surveys; the baseline assessment took place in June 2001 and the follow up assessment in September 2001.

Observations of cycle helmet wearing were carried out to validate self reported helmet wearing. Only $2 \%$ of children in participating schools rode to school, hence we organised cycling events in four schools (two in each treatment group) two weeks following completion of the follow up questionnaire to observe helmet wearing. Children were invited to attend, and the invitation purposely did not make any specific mention of cycle helmets. A member of the research team observed the proportion of children riding bikes at the event who were wearing a helmet.

\section{Sample size}

The study had $80 \%$ power to detect a difference in the percentage of children owning a helmet from $81 \%$ to $90 \%$ between the two treatment groups, at the 5\% significance level. The intra-class correlation coefficient (ICC) calculated from our sample was 0.09 . It had $80 \%$ power to detect a difference in the percentage of children always wearing a helmet from $34 \%$ to $44.5 \%$, at the $5 \%$ significance level. The ICC for helmet wearing calculated from our sample was 0.04 .

\section{Randomisation}

Participating schools were stratified by Townsend score into three strata $(0.1-2.99,3.0-6.99$, and $\geqslant 7)$. Schools were randomly allocated within each stratum to treatment group. One member of the research team generated the allocation schedule, and a second member of the research allocated the schools to treatment group team blind to the identity of each school.

\section{Blinding}

It was not possible to blind the schools or the investigators to treatment group. The data were analysed blind to treatment group.

\section{Primary analyses}

Comparability of treatment groups at baseline was assessed informally. Data were analysed using STATA version 7, SPSS version 11.0, and MLwiN version 1.1. ${ }^{28}$ Analyses were undertaken on an intention to treat basis. The primary analysis of helmet ownership and always wearing a helmet was undertaken using $t$ tests weighted by the number of children in each school. We have adjusted for baseline helmet ownership and for factors associated with helmet ownership or wearing, ${ }^{6}$ where there were large baseline differences between treatment groups using random effects logistic regression (MLwiN) to adjust for clustering. ${ }^{29}$

\section{Secondary analyses}

To assess whether the helmet + educational pack or the helmet + multifaceted intervention was more effective for children living in deprived areas we added a term for the interaction between treatment group and deprived area to the random effects logistic regression. Prior to the trial we reported that fewer children in deprived areas owned a helmet. ${ }^{6}$ To assess whether the interventions reduced this inequality, we examined the change in the relation between school level helmet ownership and deprivation at baseline and at follow up using linear regression. We used the difference in the proportion of children in each school owning a helmet (follow up proportion - baseline proportion) as the dependent variable and the median Townsend score for the school as the explanatory variable. Assumptions for the regression analyses were checked by examining plots of residuals.

Changes from baseline in helmet ownership and wearing were assessed using paired $t$ tests, weighted by the number of children in each school.

\section{RESULTS}

Figure 1 shows the progress of the 29 randomised schools and their 1213 children through the trial. Table 1 shows the characteristics of treatment groups at baseline. More children in the helmet + multifaceted intervention group were male, lived in a deprived area, and had been encouraged by their family to wear a helmet. Fewer children in the helmet + multifaceted intervention group used their bike to ride to friends and owned a helmet before the interventions started.

\section{Primary analyses}

Table 2 shows the primary outcomes. We found no significant difference between the treatment groups in either helmet ownership or wearing. The unadjusted odds ratio for cycle helmet ownership comparing the helmet + multifaceted intervention with the helmet + educational pack was 1.54 (95\% CI 0.62 to 3.84 ) and 1.51 (95\% CI 0.50 to 4.58 ) after adjusting for helmet ownership at baseline, residence in deprived area, frequency of riding bike, parental warning about danger of not wearing a helmet, and family encouragement to wear helmet. The unadjusted odds ratio for helmet wearing was 1.05 (95\% CI 0.65 to 1.68 ) and 0.98 (95\% CI 0.57 to 1.68 ) after adjusting for family encouragement to wear a helmet, best friend wearing a helmet, uses bike to ride to friends, and thinks comfort of helmet is important.

\section{Secondary analyses}

The helmet + multifaceted intervention did not appear to be more effective than the helmet + educational pack among children living in a deprived area (helmet ownership 
All primary schools with Townsend score $>0$ invited to participate $n=120$

$\downarrow$

Excluded schools $n=91$

Schools not responding to intervention $n=85$

Did not meet eligibility criteria $n=2$ (only enrolled children aged 5-7)

School declined to participate $\mathrm{n}=3$

School used as pilot for surveys and intervention $n=1$

Schools agreeing to participate and eligible $n=29$

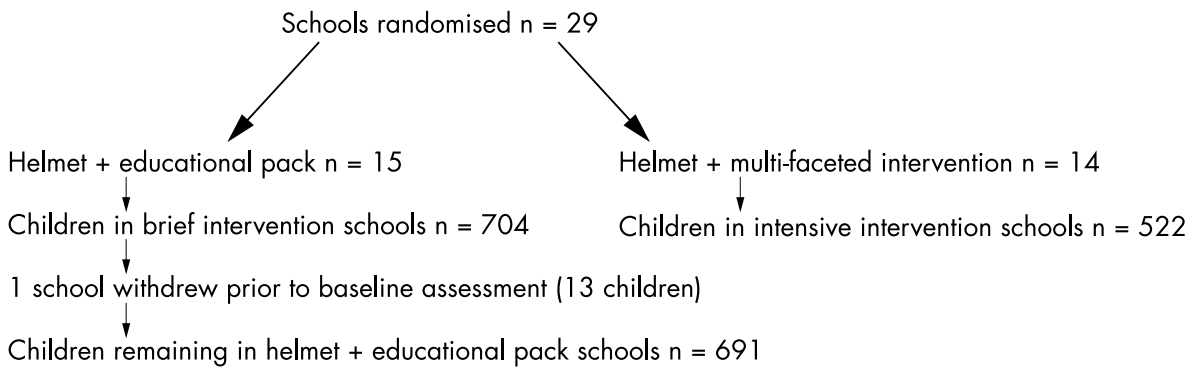

Baseline assessment

Children in school on day of survey $n=597$ $\downarrow$

Completed baseline assessment $100 \%(n=597)$
Children in school on day of survey $n=464$ $\checkmark$

Completed baseline assessment $100 \%(n=464)$
Figure 1 Progress of schools and children through the trial.

\section{Intervention}

Schools received intervention $n=14$

Children received helmet $n=351$

Children returned road safety quiz $n=324$
Schools received intervention $n=14$

Children received helmet $n=352$

Children returned road safety quiz $n=269$

Children attended cycling event $n=60$

\title{
Follow up assessment
}

Children in school on day of survey $n=605$ $\downarrow$

Completed follow up assessment $76.7 \%(n=464)$

\author{
Children in school on day of survey $n=459$ \\ $\downarrow$ \\ Completed follow up assessment $97.8 \%(n=449)$
}

$\mathrm{p}=0.90$, helmet wearing $\mathrm{p}=0.72$ ). We therefore combined the data from both treatment groups to examine the relation between deprivation and helmet ownership at baseline and at follow up. Figure 2 shows that as the degree of deprivation increased the proportion of children owning a helmet decreased, and that this was more marked at baseline than at follow up ( $b=0.027,95 \%$ CI 0.004 to $0.050, p=0.026)$. Table 3 shows a significant increase from baseline helmet ownership in both groups and in helmet wearing in the helmet + educational pack group.

\section{Cycle helmet observations}

We observed 60 children riding their bike at the cycling events in the helmet + educational pack group and 45 in the helmet + multifaceted intervention group, of which 48 (80\%) and $20(44.4 \%)$ respectively were wearing a helmet. These observed helmet wearing rates are higher than the self reported rates for always wearing a helmet at follow up for both groups (table 2).

\section{DISCUSSION}

This study is the first randomised controlled trial aimed at increasing cycle helmet use in the UK. It has shown that a free helmet and an educational pack were as effective as a free helmet plus a multifaceted intervention in increasing helmet ownership and wearing in the short term. Both interventions reduced the inequality in helmet ownership between children residing in deprived and non-deprived areas that had been present prior to the study. This is important as we have previously shown that once a helmet is owned, wearing rates do not differ between children residing in deprived and non-deprived areas. ${ }^{6}$

\section{Limitations of the study}

Our study did not include a group that did not receive any intervention because we know from previous research that providing or subsidising helmets increases ownership $^{8111416212325}$ and that education without subsidised helmets does not. ${ }^{11}$ We think it is highly unlikely that helmet ownership would increase from $50 \%$ to $80 \%$ over the three month study period for reasons other than the interventions, as there were no other cycle helmet schemes targeted at children from these schools during this time period.

We used self reported helmet ownership and wearing as the primary outcome measures, but self reports may not accurately reflect actual wearing rates. ${ }^{30}$ Observations of helmet wearing are usually used to validate self reported wearing, but as the intervention was restricted to a single 
Table 1 Characteristics of treatment groups at baseline [missing values]

\begin{tabular}{|c|c|c|}
\hline & $\begin{array}{l}\text { Helmet }+ \\
\text { educational } \\
\text { pack }(n=597)\end{array}$ & $\begin{array}{l}\text { Helmet }+ \\
\text { multifaceted } \\
\text { intervention } \\
(n=464)\end{array}$ \\
\hline Sex (male) & $285(47.7)$ & $248(53.5)$ \\
\hline Resides in deprived area & $230(44.4)[94]$ & $288(55.6)[67]$ \\
\hline $\begin{array}{l}\text { Owns bike } \\
\text { Rides bike* }\end{array}$ & $556(93.1)$ & $399(86.0)$ \\
\hline 4 or more days per week & $300(54.6)[7]$ & $209(53.6)[9]$ \\
\hline 3 days a week or less & $249(45.4)$ & $181(46.4)$ \\
\hline \multicolumn{3}{|l|}{ Rides bike* } \\
\hline To and from school & $18(3.2)$ & $5(1.3)$ \\
\hline To visit friends & $296(53.2)$ & $188(47.2)$ \\
\hline For fun & $489(88.0)$ & $348(87.2)$ \\
\hline Only when has to & $62(11.2)$ & $25(6.3)$ \\
\hline For sport & $187(33.6)$ & $149(37.3)$ \\
\hline Owns helmet* & $310(55.8)$ & $185(46.4)$ \\
\hline \multicolumn{3}{|l|}{$\begin{array}{l}\text { Told about dangers of not wearing } \\
\text { helmet by: }\end{array}$} \\
\hline Parent & $490(78.2)$ & $339(78.1)$ \\
\hline School nurse & $44(7.0)$ & $51(11.8)$ \\
\hline Teacher & $407(64.9)$ & $298(68.7)$ \\
\hline Doctor & $109(17.4)$ & $74(17.1)$ \\
\hline Policeman & $166(26.5)$ & $103(23.7)$ \\
\hline Road safety officer & $380(60.6)$ & $290(66.8)$ \\
\hline Best friend wears helmet & $217(38.0)[26]$ & $159(35.5)[16]$ \\
\hline $\begin{array}{l}\text { Had accident on bike requiring } \\
\text { medical attention }\end{array}$ & $104(17.4)$ & $96(20.7)$ \\
\hline \multicolumn{3}{|l|}{ Wears helmet when ridingt } \\
\hline Always & $86(28.3)[6]$ & $56(30.6)[2]$ \\
\hline Sometimes & $154(50.7)$ & $80(43.7)$ \\
\hline Never & $64(21.1)$ & 47 (25.7) \\
\hline
\end{tabular}

year group within each school, and only $2 \%$ of children rode to school, we were limited in how we could conduct observations. We piloted observations with a year 5 teacher from participating schools and a researcher driving in the catchment area of the school, with the teacher identifying year 5 children from the school. We observed 99 children during five observations, only nine of which belonged to year 5, making it unfeasible to observe sufficient children within

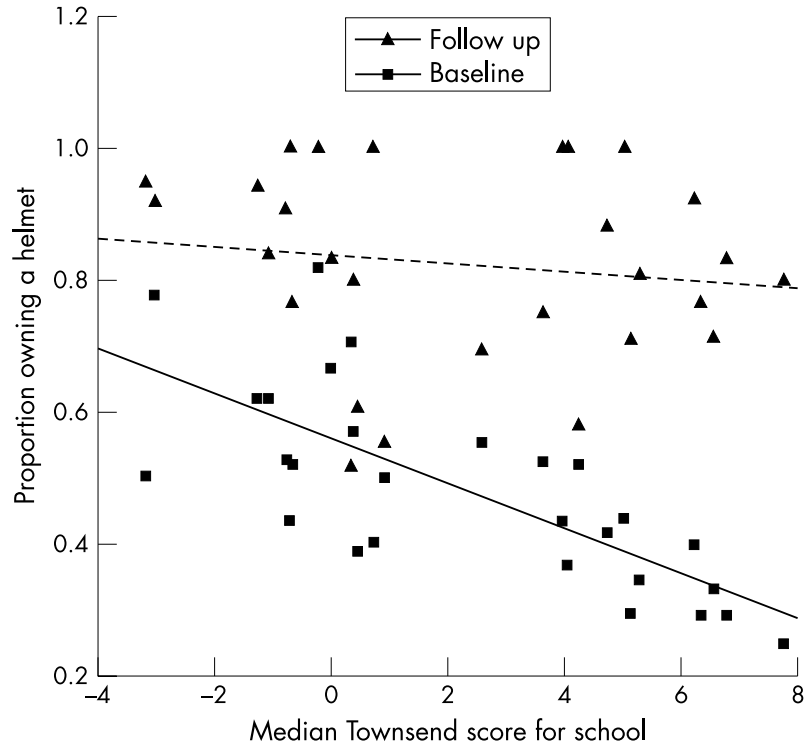

Figure 2 Scatterplot of the proportion of children owning a helmet in each school against the median Townsend score for each school, at baseline and at follow up.

the time scale and budget of the trial. We therefore organised cycling events at schools in both treatment groups after the follow up questionnaire to observe helmet wearing. The observations found higher wearing rates than self reported rates of always wearing a helmet. These findings are similar to a large study that observed more than 900 children riding and performed classroom surveys of more than 8000 children; it found classroom self reported always wearing rates (15\%) were lower than observed wearing rates $(20 \%)$, self reported use of helmet on day of survey $(26 \%)$, or parent report of child always wearing a helmet $(37 \%) .^{31}$ This suggests classroom self reported rates of always wearing a helmet may be the most conservative estimates of helmet wearing rates.

The response rate to the follow up survey was lower in the helmet + educational pack group than the helmet + multifaceted intervention group, and this may have biased our

Table 2 Number of children owning and always wearing a helmet by school and treatment group post-intervention (percentage)

\begin{tabular}{|c|c|c|c|c|c|c|c|}
\hline \multicolumn{4}{|c|}{ Owns a helmet } & \multicolumn{4}{|c|}{ Always wears a helmet } \\
\hline $\begin{array}{l}\text { School } \\
\text { number }\end{array}$ & $\begin{array}{l}\text { Helmet + multifaceted } \\
\text { intervention }\end{array}$ & $\begin{array}{l}\text { School } \\
\text { number }\end{array}$ & $\begin{array}{l}\text { Helmet + educational } \\
\text { pack }\end{array}$ & $\begin{array}{l}\text { School } \\
\text { number }\end{array}$ & $\begin{array}{l}\text { Helmet + multifaceted } \\
\text { intervention }\end{array}$ & $\begin{array}{l}\text { School } \\
\text { number }\end{array}$ & $\begin{array}{l}\text { Helmet + educational } \\
\text { pack }\end{array}$ \\
\hline 1 & $38 / 47(81)$ & 15 & $5 / 7(71)$ & 1 & $10 / 38(26)$ & 15 & $2 / 5(40)$ \\
\hline 2 & $18 / 18(100)$ & 16 & $18 / 31(58)$ & 2 & $8 / 17(47)$ & 16 & $8 / 18(44)$ \\
\hline 3 & $15 / 29(52)$ & 17 & $30 / 34(88)$ & 3 & $7 / 15$ (47) & 17 & $12 / 30(40)$ \\
\hline 4 & $12 / 15(80)$ & 18 & $13 / 17(76)$ & 4 & $3 / 11$ (28) & 18 & $2 / 13(15)$ \\
\hline 5 & $12 / 13(92)$ & 19 & $15 / 18(83)$ & 5 & $2 / 11(18)$ & 19 & $4 / 15(27)$ \\
\hline 6 & $20 / 22(91)$ & 20 & $34 / 49(69)$ & 6 & $6 / 20(30)$ & 20 & $4 / 34(12)$ \\
\hline 7 & $20 / 20(100)$ & 21 & $6 / 6(100)$ & 7 & $4 / 19(21)$ & 21 & $2 / 6(33)$ \\
\hline 8 & $17 / 24(71)$ & 22 & $16 / 17(94)$ & 8 & $5 / 17(29)$ & 22 & $4 / 16(25)$ \\
\hline 9 & $40 / 50(80)$ & 23 & $14 / 23(61)$ & 9 & $14 / 40(35)$ & 23 & $6 / 14(43)$ \\
\hline 10 & $30 / 40(75)$ & 24 & $92 / 100(92)$ & 10 & $8 / 30(27)$ & 24 & $49 / 92(53)$ \\
\hline 11 & $55 / 55(100)$ & 25 & $15 / 18(83)$ & 11 & $25 / 55(45)$ & 25 & $3 / 15(20)$ \\
\hline 12 & $22 / 22(100)$ & 26 & $49 / 64(77)$ & 12 & $10 / 22(45)$ & 26 & $11 / 49(22)$ \\
\hline 13 & $5 / 9(56)$ & 27 & $19 / 20(95)$ & 13 & $0 / 5(0)$ & 27 & $4 / 19(21)$ \\
\hline 14 & $10 / 10(100)$ & 28 & $26 / 31(84)$ & 14 & $2 / 10(20)$ & 28 & $10 / 26(38)$ \\
\hline \multicolumn{8}{|c|}{ Mean percentage across schools (SE)* } \\
\hline & $84.0(4.2)$ & & $80.9(3.8)$ & & $33.1(2.9)$ & & $33.8(5.7)$ \\
\hline \multicolumn{8}{|c|}{ Difference between means ( $95 \% \mathrm{CI})$} \\
\hline & & & \multicolumn{3}{|c|}{$3.0(-8.5$ to 14.6$), p=0.59$} & \multicolumn{2}{|c|}{$-0.6(-13.8$ to 12.5$), p=0.92$} \\
\hline
\end{tabular}


Table 3 Changes in cycle helmet ownership and wearing from baseline by treatment group

\begin{tabular}{|c|c|c|c|c|}
\hline & $\begin{array}{l}\text { Mean \% in } \\
\text { schools at } \\
\text { baseline (SE) }\end{array}$ & $\begin{array}{l}\text { Mean \% in } \\
\text { schools at } \\
\text { follow up (SE) }\end{array}$ & $\begin{array}{l}\text { Difference between } \\
\text { means }(95 \% \mathrm{Cl})\end{array}$ & $p$ value \\
\hline \multicolumn{5}{|l|}{ Helmet + educational pack } \\
\hline Owns a helmet & $56.2(5.6)$ & $80.9(3.8)$ & 24.7 (15.9 to 33.5$)$ & $<0.001$ \\
\hline Always wears helmet & $26.8(5.0)$ & $33.8(5.8)$ & $6.9(0.1$ to 13.8$)$ & 0.048 \\
\hline Sometimes wears helmet & $52.0(4.4)$ & $53.9(3.5)$ & $1.9(-6.0$ to 9.9$)$ & 0.61 \\
\hline Never wears helmet & $21.2(3.7)$ & $12.3(3.1)$ & $-8.9(-16.3$ to -1.4$)$ & 0.024 \\
\hline \multicolumn{5}{|c|}{ Helmet + multifaceted intervention } \\
\hline Owns a helmet & $46.4(3.6)$ & $84.0(4.3)$ & 37.5 (22.8 to 52.2 ) & $<0.001$ \\
\hline Always wears helmet & $30.4(3.6)$ & $33.1(3.0)$ & $2.7(-7.3$ to 12.7$)$ & 0.57 \\
\hline Sometimes wears helmet & $43.8(3.9)$ & $54.2(2.8)$ & $10.4(-0.4$ to 21.2$)$ & 0.057 \\
\hline Never wears helmet & $25.7(6.4)$ & $12.6(2.1)$ & $-13.1(-26.7$ to 0.7$)$ & 0.061 \\
\hline \multicolumn{5}{|c|}{$\begin{array}{l}\text { Denominators for: } \\
\text { Helmet ownership at baseline: helmet }+ \text { educational pack }=556 \text {, helmet }+ \text { multifaceted intervention }=399 \\
\text { Helmet ownership at follow up: helmet + educational pack }=435 \text {, helmet }+ \text { multifaceted intervention }=374 \\
\text { Helmet wearing at baseline: helmet }+ \text { educational pack }=304 \text {, helmet }+ \text { multifaceted intervention }=183 \\
\text { Helmet wearing at follow up: helmet + educational pack }=352 \text {, helmet + multifaceted intervention }=310\end{array}$} \\
\hline
\end{tabular}

results. If non-responders in the helmet + educational pack group were less likely to own or wear helmets than responders, this would tend to underestimate the effect of the helmet + multifaceted intervention. The worst case scenario is that helmet wearing rates among the non-responders in the helmet + educational pack group did not increase from those at baseline. Using the ownership and wearing rates for each school at baseline, we estimated the numbers of nonresponders in each school owning and wearing a helmet at follow up. Under this scenario, the helmet + educational pack group helmet ownership rate at follow up would reduce to $75 \%$ and the percentage always wearing a helmet to $33 \%$. The differences between these figures and the helmet + multifaceted intervention group ownership and wearing rates would not alter the conclusions we have drawn from this study.

Finally we have only been able to show short term effects of the interventions used in this study. Future research should consider the use of a longer follow up period to determine the length of time for which the interventions remain effective and to assess whether helmet wearing continues into the teenage years, as wearing rates are usually lower in this age group. ${ }^{26}{ }^{32-37}$

\section{How this study compares to previous studies}

Several studies have assessed the impact of educational programmes plus subsidised helmets in low income communities. ${ }^{14} 161938$ Two showed increased helmet use among low income children, ${ }^{16}{ }^{38}$ one found requesting parents to pay a small amount towards helmets was as effective as providing free helmets in increasing helmet use, ${ }^{14}$ and the fourth found subsidised helmets did not increase helmet use among children from low income families. ${ }^{19}$ Our findings add weight to the three studies reporting the positive effect of helmet subsidies in low income communities, and confirm these findings in a UK context.

Studies that have undertaken subgroup analyses assessing the impact of educational interventions plus cycle helmet provision by social group have produced mixed results. One study found the intervention was associated with higher helmet wearing rates among children from low income communities, ${ }^{8}$ while others found the intervention to be less effective in low income communities. ${ }^{7}{ }^{18} 24$ We did not find a significant difference in the effectiveness of the interventions by residence in a deprived area, which is encouraging; however, the study was not designed to be adequately powered to detect such a difference, so care must be taken in interpreting these results.

\section{Implications for practice and research}

Most reported helmet promotion programmes have employed multifaceted interventions and it is often not clear how each component contributes to the overall effectiveness of the programme. This study has shown that the many time consuming (and potentially expensive) components of a multifaceted intervention conferred little if any advantage in terms of helmet ownership or wearing over a simpler intervention, at least in the short term. In addition the interventions reduced the inequality in helmet ownership associated with living in a deprived area. Bicycle helmets are effective in reducing head and brain injuries and have been shown to be cost effective. ${ }^{39}$ Primary Care Trusts and other agencies wishing to reduce both childhood injuries and inequalities should consider providing free helmets with an educational pack. More research is necessary to determine the length of the observed effect, particularly with respect to helmet wearing into the teenage years. Concerns have been expressed that increasing cycle helmet use may be associated with an increase in risk taking by helmeted cyclists ${ }^{40-42}$ and a reduction in cycling and its associated health benefits. ${ }^{141}$ Agencies working to improve child health will need to implement other interventions in addition to cycle helmet promotion to achieve maximum injury reduction. Similarly maximising childhood exercise will require the promotion of exercise in its broadest sense, not just cycling.

\section{ACKNOWLEDGEMENTS}

We would like to thank Kath Needham the project administrator, plus the members of the "Lids for Kids" project team who were Dr David Thomas, Dr Frank Coffey, Dr Stephanie Smith, Ms Kate Fletcher, Mr Roger Whitfield, Ms Hazel Hoskyns, Ms Sue Spanswick, and Ms Pauline Brown. We would also like to thank the children, teachers, and administrative staff at the participating schools and Ms Carol Coupland for statistical advice.

\section{Authors' affiliations}

D Kendrick, S Royal, Division of General Practice, University Park, Nottingham, UK

Funding: Nottingham Health Authority

\section{REFERENCES}

1 Thompson DC, Rivara FP, Thompson RS. Helmets for preventing head and facial injury in bicyclists [Cochrane Review]. The Cochrane Library Issue 2. Oxford: Update Sofrware, 2000.

2 Department of the Environment, Transport and the Regions. Factsheet: Pedal cyclists in road accidents: Great Britain 1998. London: DETR, 1999. 
3 Cook A, Sheikh A. Trends in serious head injuries among cyclists in England: analysis of routinely collected data. BMJ 2000;321:1055.

4 Roberts IG. Cause specific social class mortality differentials for child injury and poisoning in England and Wales. J Epidemiol Community Health 1997; 51:334-5.

5 Hippisley-Cox J, Groom L, Kendrick D, et al. Cross sectional survey of socioeconomic variations in severity and mechanism of childhood injuries in Trent 1992-7. BMJ 2002;324:1132.

6 Anon. A survey of bicycle helmet use among school children in deprived areas of Nottingham, UK. 6th World Conference Injury Prevention and Control; May 2002; Montreal. Les Presses de l'Universite de Montreal, 2002:12-15.

7 Parkin PC, Spence $\amalg, H u$ X, et al. Evaluation of a promotional strategy to increase bicycle helmet use by children. Pediatrics 1993;91:772-7.

8 DiGuiseppi CG, Rivara FP, Koepsell TD, et al. Bicycle helmet use by children. Evaluation of a community-wide helmet campaign. JAMA 1989;262:2256-61

9 Cushman R, Down J, MacMillan N, et al. Helmet promotion in the emergency room following a bicycle injury: a randomized trial. Pediatrics 1991;88:43-7.

10 Cushman R, James W, Waclawik H. Physicians promoting bicycle helmets for children: a randomized trial. Am J Public Health 1991;81:1044-6.

11 Morris BA, Trimble NE. Promotion of bicycle helmet use among schoolchildren: a randomized clinical trial. Can J Public Health 1991;82:92-4.

12 Labrecque M, Dostaler LP, Houde A, et al. [Can physicians efficaciously promote the purchase of bicycle helmets?]. Canadian Family Physician 1994;40:1132-7.

13 Macarthur C, Parkin PC, Sidky M, et al. Evaluation of a bicycle skills training program for young children: a randomized controlled trial. Inj Prev $1998 \cdot 4: 116-21$.

14 Kim AN, Rivara FP, Koepsell TD. Does sharing the cost of a bicycle helmet help promote helmet use? Inj Prev 1997;3:38-42.

15 Stevens MM, Olson AL, Gaffney CA, et al. A pediatric, practice-based, randomized trial of drinking and smoking prevention and bicycle helmet, gun, and seatbelt safety promotion. Pediatrics 2002;109:490-7.

16 Britt J, Silver I, Rivara FP. Bicycle helmet promotion among low income preschool children. Inj Prev 1998;4:280-3.

17 Floerchinger-Franks G, Machala M, Goodale K, et al. Evaluation of a pilot program in rural schools to increase bicycle and motor vehicle safety. J Community Health 2000;25:113-24.

18 Farley C, Haddad S, Brown B. The effects of a 4-year program promoting bicycle helmet use among children in Quebec. Am J Public Health 1996;86:46-51.

19 Parkin PC, Hu X, Spence $\amalg$, et al. Evaluation of a subsidy program to increase bicycle helmet use by children of low-income families. Pediatrics 1995;96(2 pt 1):283-7.

20 Cote TR, Sacks JJ, Lambert-Huber DA, et al. Bicycle helmet use among Maryland children: effect of legislation and education. Pediatrics 1992; 89(6 pt 2):1216-20.

21 Lee AJ, Mann NP, Takriti R. A hospital led promotion campaign aimed to increase bicycle helmet wearing among children aged 11-15 living in West Berkshire 1992-98. Inj Prev 2000;6:151-3.
22 Pendergrast RA, Ashworth CS, DuRant RH, et al. Correlates of children's bicycle helmet use and short-term failure of school-level interventions. Pediatrics 1992;90:354-8.

23 Watts $D, O^{\prime}$ Shea N, Flynn E, et al. Effect of a bicycle safery program and free bicycle helmet distribution on the use of bicycle helmets by elementary school children. J Emerg Nurs 1997;23:417-19.

24 Towner P, Marvel MK. A school-based intervention to increase the use of bicycle helmets. Fam Med 1992;24:156-8

25 Liller KD, Smorynski A, McDermott RJ, et al. The MORE HEALTH bicycle safety project. Journal of School Health 1995;65:87-90.

26 Cryer PC, Cole J, Davidson LL, et al. Rates of, and the factors affecting, cycle helmet use among secondary schoolchildren in East Sussex and Kent. Inj Prev 1998;4:106-10.

27 Lee AJ. The Bicycle Helmet Initiative Trust: guidelines for setting up community based cycle helmet programmes. Sheffield: Bicycle Helmet Initiative Trust, 2000

28 MLwiN [program]. 1.10.006 version. London: Institute of Education, University of London., 2000.

29 Ukoumunne OC, Gulliford MC, Chinn S, et al. Methods for evaluating areawide and organisation-based interventions in health and health care: a systematic review. Health Technol Assess 1999;3(5):iii-92.

30 Schieber RA, Sacks JJ. Measuring community bicycle helmet use among children. Public Health Reports 2001;116:113-21.

$31 \mathrm{Ni} \mathrm{H}$, Sacks JJ, Curtis L, et al. Evaluation of a statewide bicycle helmet law via multiple measures of helmet use. Arch Pediatr Adolesc Med 1997; 151:59-65.

32 Berg P, Westerling R. Bicycle helmet use among schoolchildren -the influence of parental involvement and children's attitudes. Inj Prev 2001;7:218-22.

33 Finch CF. Teenagers' attitudes towards bicycle helmets three years after the introduction of mandatory wearing. Inj Prev 1996;2:126-30.

34 Harlos S, Warda L, Buchan N, et al. Urban and rural patterns of bicycle helmet use: factors predicting usage. Inj Prev 1999:5:183-8.

35 Hu X, Wesson DE, Parkin PC, et al. Current bicycle helmet ownership, use and related factors among school-aged children in metropolitan Toronto. Canadian Journal of Public Health. Revue Canadienne de Sante Publique 1994;85:121-4.

36 Liller KD, Morissette B, Noland V, et al. Middle school students and bicycle helmet use: knowledge, attitudes, beliefs, and behaviors. Journal of School Health 1998;68:325-8.

37 Wardle S, lqbal Z. Cycle helmet ownership and wearing; results of a survey in South Staffordshire. J Public Health Med 1998;20:70-7.

38 Hendrickson SG, Becker H. Impact of a theory based intervention to increase bicycle helmet use in low income children. Inj Prev 1998;4:126-31.

39 Miller TR, Levy DT. Cost-outcome analysis in injury prevention and control: eighty-four recent estimates for the United States. Med Care 2000;38:562-82.

40 Thompson DC, Thompson RS, Rivara FP. Risk compensation theory should be subject to systematic reviews of the scientific evidence. Inj Prev 2001;7:86-8.

41 Adams J, Hlilman M. The risk compensation theory and bicycle helmets. Ini Prev 2001;7:89-91.

42 Adams J, Hillman M. Bicycle helmets. Risk taking is influenced by people's perception of safety and danger. BMJ 2001;322:1063-4. 


\section{PostScript}

\section{LETTERS}

Radiological sign of a long line in the ascending lumbar vein

We would like to draw attention to a useful radiological sign indicating that a percutaneous central venous catheter may be in the ascending lumbar vein. In our neonatal unit there have been two confirmed cases where the ascending lumbar vein had inadvertently been cannulated. In both these cases a loop in the line had been noted in the region of the ileo-femoral vein (see figs 1 and 2). This "looping" or bend in the line is also seen in the picture recently published by $\mathrm{De},{ }^{5}$ and in other papers. ${ }^{1-3}$

That this complication occurs almost exclusively on the left ${ }^{2}$ has been attributed to the unique anatomy of the left ileo-femoral vein compared to the right.' We believe that the local anatomy of the left ileo-femoral vein may also explain why the line loops when inadvertently entering the left ascending lumbar vein (fig 3). One can appreciate that, when the ascending lumbar vein is seen on the lateral ${ }^{1}$ and lateral-oblique view, ${ }^{4}$ and compared with the anterior posterior view, the vein can be seen to descend into the pelvis and then enter the ascending lumbar vein at an angle. On an $x$ ray the line will then project a loop or bend.

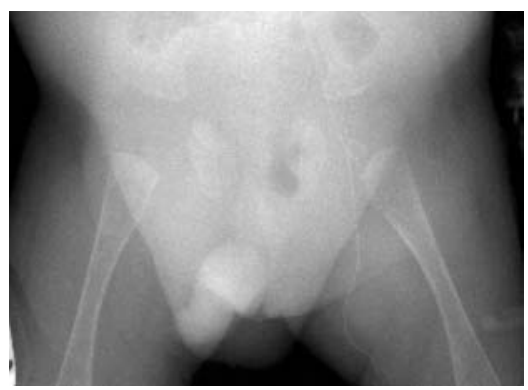

Figure 1

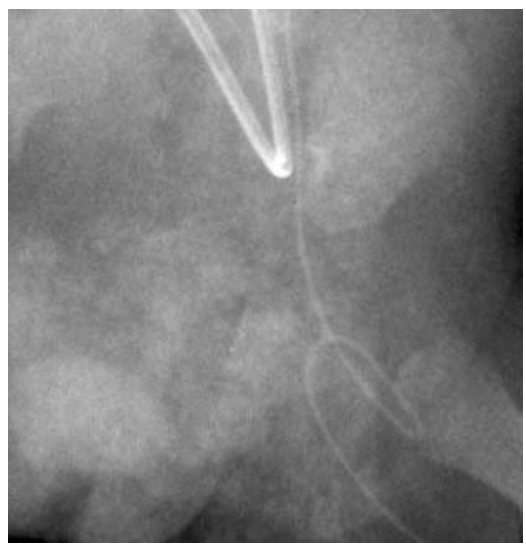

Figure 2

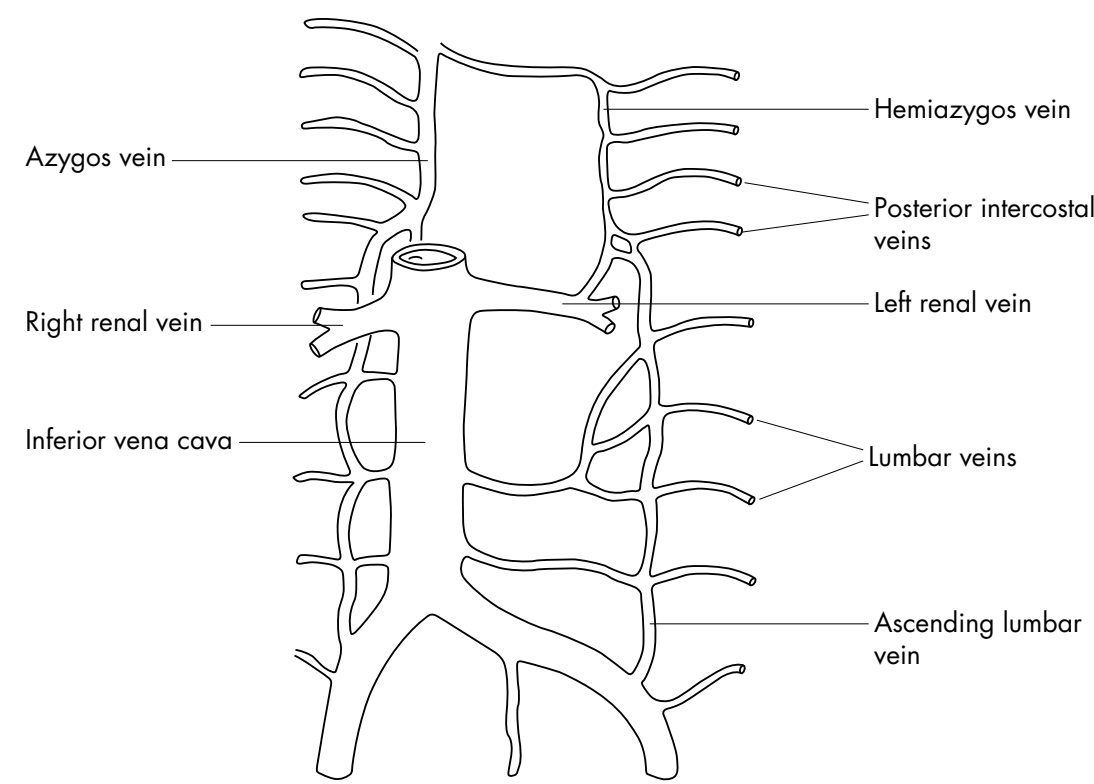

Figure 3 Reproduced with kind permission from British Journal of Radiology: RS Oeppen and K Tung. Retrograde venous invasion causing vertebral metastases in renal cell carcinoma. $\mathrm{Br} J$ Radiol 2001;74:759-61.

Another factor that may contribute to the appearance of the loop or bend is that it is probably difficult to advance the line up the narrow ascending lumbar vein, and therefore when trying to thread the line to its calculated length the line will "buckle" at this point

Any loop or bend of a contrast filled line in the left ileo-femoral region should be regarded as a sign that the line has entered the ascending lumbar vein and pull the line back because the lumbar venous plexus will not always be visualised with contrast. There are serious complications of an unrecognised malpositioned long line. ${ }^{2}$ We feel that awareness of this radiological sign would facilitate early recognition and would prevent serious morbidity.

B C Schoonakker, D Harding Department of Neonatology, UBHT, St Michaels, Bristol BS2 8BJ, UK; bernard.schoonakker @ubht.swest.nhs.uk

doi: $10.1136 /$ adc. 2005.072595

Competing interes: none declared

\section{References}

1 Vidwans A, Neumann DP, Hussain N, et al. Diagnosis and management of spinal epidural space extravasation complicating percutaneous central venous line placement in a premature infant: case report and review of literature. Conn Med 2000;64:79-82.

2 Clarke P, Wadhawan R, Smyth J, et al. Parenteral nutrition retrieved by lumbar puncture following left saphenous vein catheterization. J Paediatr Child Health 2003:39:386-9.

3 Odaibo F, Fajardo CA, Cronin C. Recovery of intralipid from lumbar puncture after migration of saphenous vein catheter. Arch Dis Child 1992:67:1201-3.
4 Miller MH, Handel SF, Coan JD. Transfemora lumbar epidural venography. Am J Roentgenol 1976; 126:1003-9.

5 De A, Imam A. Long line complication: accidental cannulation of ascending lumbar vein. Arch Dis Child 2005;90:48.

\section{Changing incidence of respiratory presentations in primary care fact or artefact?}

Recently reported declines in asthma morbidity $^{1}$ may be difficult to interpret as they could reflect not only changes in incidence, but also changing disease severity, patient expectations, healthcare provision, and efficacy of pharmacological management. Indeed, it has been suggested that general practitioners may choose differing diagnostic labels for respiratory disease to justify prescribing medication. ${ }^{2}$

In view of these apparent inconsistencies, we used 37 practices taking part in the Scottish Continuous Morbidity Recording project (CMR) to determine possible changes in diagnostic fashion. Changes in the yearly age specific incidence (per 1000 population) were ascertained for the recording of diagnoses and symptoms including asthma, wheeze, and other respiratory illnesses including acute bronchitis, bronchiolitis, lower respiratory tract infection (LRTI), croup, chest infection, and acute respiratory infections combined (Read codes (version 2) used listed in table 1). The CMR project's data collection processes have been described previously. ${ }^{3}$ Two child age groups were defined, namely those aged under 5 years of age $(n=12693$ children) and those aged 514 years $(n=30165$ children $)$. Trends of disease incidence for six 12-month periods starting 31 March 1996 and ending 31 March 
Table 1 Respiratory illnesses studied; Read codes

\begin{tabular}{|c|c|}
\hline Respiratory disease & Read code \\
\hline Acute bronchitis & $\begin{array}{l}\mathrm{H} 060 \text { and } \\
\text { below }\end{array}$ \\
\hline $\begin{array}{l}\text { Acute respiratory } \\
\text { infections }\end{array}$ & $\mathrm{HO}$ and below \\
\hline Asthma & $\begin{array}{l}\mathrm{H} 33 \text { and } \\
\text { below }\end{array}$ \\
\hline Bronchiolitis & $\begin{array}{l}\mathrm{H} 061 \text { and } \\
\text { below }\end{array}$ \\
\hline Chest infection & $\mathrm{H06zO}$ \\
\hline Croup & $\mathrm{H} 044$ \\
\hline $\begin{array}{l}\text { Lower respiratory tract } \\
\text { infection }\end{array}$ & $\mathrm{HOCzl}$ \\
\hline Wheeze & 1737, R0609 \\
\hline
\end{tabular}

2002 were tested for linear association using the Mantel-Haenszel $\chi^{2}$ test, giving $p$ for trend using Epi Info version 6.0 (Centers for Disease Control and Prevention, Atlanta, Georgia, USA). The study protocol was approved by the Scientific Advisory Group of the Primary Care Clinical Informatics Unit-Research, which is the registered guardian for these anonymised data.

In the youngest age group, there was a declining trend in the incidence of asthma $(p<0.001)$, with the rate of wheeze incidence more than doubling over the study period. There was a small increase over the study period in the number of patients presenting with both asthma and wheeze $(n=16)$. Increases in the six year study period were observed for all other diseases considered as an alternative diagnosis for asthma (diagnostic transfer) $(\mathrm{p}<0.001)$.

Table 2 Annual incidence of asthma and wheeze and lower respiratory disease combined in children under 5 years and 5-14 years

\begin{tabular}{|c|c|c|c|c|c|}
\hline \multirow[b]{2}{*}{ Diagnosis } & \multirow[b]{2}{*}{ Year } & \multirow{2}{*}{$\begin{array}{l}\text { 1st diagnoses } \\
\text { Incident cases, n }\end{array}$} & \multirow{2}{*}{$\begin{array}{l}\text { Incidence per } \\
1000\end{array}$} & \multicolumn{2}{|c|}{$95 \% \mathrm{Cl}$} \\
\hline & & & & Lower & Upper \\
\hline \multicolumn{6}{|c|}{ Under 5 years old } \\
\hline \multirow[t]{6}{*}{ Asthma* } & March 1997 & 277 & 21.8 & 19.4 & 24.4 \\
\hline & March 1998 & 256 & 19.7 & 17.5 & 22.3 \\
\hline & March 1999 & 250 & 19.4 & 17.2 & 21.9 \\
\hline & March 2000 & 195 & 15.1 & 13.4 & 17.7 \\
\hline & March 2001 & 190 & 14.9 & 12.9 & 17.1 \\
\hline & March 2002 & 211 & 16.6 & 14.5 & 19.0 \\
\hline \multirow[t]{6}{*}{ Wheeze ${ }^{*}$} & March 1997 & 51 & 4.0 & 3.1 & 5.3 \\
\hline & March 1998 & 65 & 5.0 & 3.9 & 6.4 \\
\hline & March 1999 & 120 & 9.3 & 7.8 & 11.1 \\
\hline & March 2000 & 135 & 10.5 & 8.9 & 12.4 \\
\hline & March 2001 & 112 & 8.8 & 7.3 & 10.6 \\
\hline & March 2002 & 123 & 9.7 & 8.1 & 11.6 \\
\hline \multirow{6}{*}{$\begin{array}{l}\text { Diagnostic } \\
\text { transfer* }\end{array}$} & March 1997 & 1007 & 66 & 51.04 & 84.00 \\
\hline & March 1998 & 1032 & 69.3 & 53.94 & 87.69 \\
\hline & March 1999 & 1024 & 86 & 68.78 & 106.24 \\
\hline & March 2000 & 1104 & 102.2 & 83.35 & 124.07 \\
\hline & March 2001 & 1161 & 104.1 & 85.06 & 126.15 \\
\hline & March 2002 & 1220 & 104.4 & 85.33 & 126.48 \\
\hline \multirow{6}{*}{$\begin{array}{l}\text { Combined } \\
\text { symptoms and } \\
\text { disease }^{*}\end{array}$} & March 1997 & 1265 & 99.38 & 80.80 & 120.98 \\
\hline & March 1998 & 1291 & 99.48 & 80.89 & 121.08 \\
\hline & March 1999 & 1326 & 102.86 & 83.94 & 124.80 \\
\hline & March 2000 & 1353 & 104.96 & 85.84 & 127.09 \\
\hline & March 2001 & 1387 & 108.67 & 89.20 & 131.16 \\
\hline & March 2002 & 1450 & 114.24 & 94.25 & 137.24 \\
\hline \multicolumn{6}{|l|}{ 5-14 years old } \\
\hline \multirow[t]{6}{*}{ Asthma ${ }^{*}$} & March 1997 & 360 & 13.1 & 11.8 & 14.5 \\
\hline & March 1998 & 399 & 13.8 & 12.5 & 15.2 \\
\hline & March 1999 & 371 & 12.3 & 11.1 & 13.6 \\
\hline & March 2000 & 302 & 10.0 & 9.0 & 11.2 \\
\hline & March 2001 & 281 & 9.3 & 8.3 & 10.5 \\
\hline & March 2002 & 308 & 10.2 & 9.1 & 11.4 \\
\hline \multirow{6}{*}{ Wheeze* } & March 1997 & 30 & 1.1 & 0.8 & 1.6 \\
\hline & March 1998 & 48 & 1.7 & 1.3 & 2.2 \\
\hline & March 1999 & 53 & 1.8 & 1.4 & 2.3 \\
\hline & March 2000 & 68 & 2.3 & 1.8 & 2.9 \\
\hline & March 2001 & 58 & 1.9 & 1.5 & 2.5 \\
\hline & March 2002 & 61 & 2.0 & 1.6 & 2.6 \\
\hline \multirow{6}{*}{$\begin{array}{l}\text { Diagnostic } \\
\text { transfer* }\end{array}$} & March 1997 & 594 & 21.54 & 13.41 & 32.81 \\
\hline & March 1998 & 657 & 22.76 & 14.37 & 34.28 \\
\hline & March 1999 & 570 & 18.93 & 11.36 & 29.64 \\
\hline & March 2000 & 516 & 17.14 & 9.99 & 27.45 \\
\hline & March 2001 & 654 & 21.68 & 13.52 & 32.98 \\
\hline & March 2002 & 770 & 25.53 & 16.58 & 37.58 \\
\hline \multirow{6}{*}{$\begin{array}{l}\text { Combined } \\
\text { symptoms and } \\
\text { disease }\end{array}$} & March 1997 & 950 & 34.45 & 23.91 & 48.08 \\
\hline & March 1998 & 1067 & 36.97 & 26.01 & 51.00 \\
\hline & March 1999 & 968 & 32.15 & 22.00 & 45.40 \\
\hline & March 2000 & 856 & 28.43 & 18.94 & 41.03 \\
\hline & March 2001 & 968 & 32.09 & 21.95 & 45.33 \\
\hline & March 2002 & 1086 & 36.00 & 25.20 & 49.88 \\
\hline
\end{tabular}

Overall, there was an increase in incidence rates for those recorded as having any one study disease or symptom $(\mathrm{p}<0.001)$. Similar trends for asthma and wheeze were found for children aged 5-14 years.

In the present study, physician diagnostic labelling has been shown to change with time. There was a clear reduction in the labelling of the incident cases of asthma and evidence was also found for an increase in other diseases and symptoms that could be used as alternative diagnostic labels for asthma. Although these changes may have been influenced by British asthma guidelines published in 1997, ${ }^{4}$ which reiterated the importance of a correct diagnosis, changes in computer coding procedures should not have occurred, as a standard Read code dictionary was used by trained CMR practice data operators throughout the study period. These trends may have implications for large scale population surveys or studies that utilise data collected from routine clinical activity, leading to the accidental reporting of artefact.

\section{Acknowledgements}

The authors are grateful to the general practitioners who provided practice data to the Primary Care Clinical Informatics Unit-Research.

C R Simpson, A J Lee, M W Taylor

Department of General Practice \& Primary Care, The University of Aberdeen, Scotland, UK

P J Helms

Department of Child Health, University of Aberdeen, Scotland, UK

Correspondence to: Dr C R Simpson, Department of General Practice \& Primary Care, Foresterhill Health Centre, Westburn Road, The University of Aberdeen, Aberdeen AB25 2AY, Scotland, UK; c.simp@abdn.ac.uk

doi: $10.1136 /$ adc. 2004.063834

Competing interests: Peter J Helms has performed consultancies for Glaxo-Wellcome, Astra-Zeneca, and Merck Sharp \& Dohme. Michael Taylor, Amanda Lee, and Colin Simpson have no competing interests.

\section{References}

1 Sunderland RS, Fleming DM. Continuing decline in acute asthma episodes in the community. Arch Dis Child 2004;89:282-5.

2 Thomas $M$. The management of acute lower respiratory tract infections in adults in primary care. Prim Care Respir J 2000:9:4-7.

3 McAlister FA, Murphy NF, Simpson CR, et al. Influence of socioeconomic deprivation on the primary care burden and treatment of patients with a diagnosis of heart failure in general practice in Scotland: population based study. BMJ 2004;328: 1110

4 British Asthma Guidelines Coordinating

Committee. British guidelines on asthma management: 1995 review and position statement. Thorax 1997;52(suppl 1):S2-20.

\section{Patient choice in medicine taking: religious sensitivities must be respected}

Children often do not have choice in medicine taking, as it is typically their parents who agree, on their behalf, to receive prescribed treatments. Exploring parents' (and wherever possible also children's) beliefs about choice of medication is however important, ${ }^{1}$ particularly so when strong religious beliefs about 
Table 1 Examples of bovine, pork, and blood derived mediations and possible alternatives

\begin{tabular}{ll}
\hline $\begin{array}{l}\text { Blood, bovine, and pork derived mediations } \\
\text { (generic and proprietary names) }\end{array}$ & $\begin{array}{l}\text { Alternative preparations } \\
\text { (generic and proprietary names) }\end{array}$ \\
\hline $\begin{array}{l}\text { Blood } \\
\text { Human albumin }\end{array}$ & $\begin{array}{l}\text { Crystalloid e.g. saline } \\
\text { Factor VIII }\end{array}$ \\
$\begin{array}{l}\text { Rovine } \\
\text { Amoxicillin (Amoxil) capsules }\end{array}$ & Amoxictor VIII \\
Beef insulin (Amoxil) syrup \\
$\begin{array}{l}\text { Omeprazole (Losec) } \\
\text { Pork }\end{array}$ & Recombinant insulin \\
Portant alfa (Curosurf) & Omeprazole (MUPS) dispersible tablets \\
MMR vaccine (MMR-II) & Colfosceril palmitate (Exosurf) \\
Heparin calcium (Calciparine) & MMR vaccine (Priorix) \\
Isophane insulin (Hypurin) & Heparin (Arixtra) \\
Pancreatin (Pancrease) & Isophane insulin (Human insulatard) \\
\hline
\end{tabular}

contents of medications may be present, as a failure to do so may result in unintended harm and negatively impact on compliance.

In a multicultural context, it is essential that prescribers have a minimal level of awareness of parent's religious sensitiveness so that these can be considered when prescribing (table 1). Jehovah's Witnesses, for example, may choose to avoid blood derived products. ${ }^{2}$ Jewish law forbids any oral use of medication containing glycerol, stearates, lactose, and porcine products. ${ }^{3}$ Similarly, Hindus and Sikhs may be offended by medication containing animal products, particularly bovine derived products (for example, gelatine containing capsules). Islamic rulings that prohibit any systemic ingestion of pork or alcohol also need to be considered in the context of prescribing decisions involving Muslims. ${ }^{4}$

A practical way of ensuring that health professionals have sufficient information about treatment options available would be for the British National Formulary to clearly indicate which preparations contain blood, animal, and alcohol derivatives, and, where possible, suggest suitable alternatives. The proposed electronic health records will facilitate the seamless sharing of patient information among multiple healthcare providers. This will therefore offer an additional systematic approach for routinely collecting information, and through use of "prescribing alerts" can help inform clinicians about patient preferences in relation to medications.

But beliefs need to be balanced against clinical need. Recognising that many religious traditions offer a degree of relaxation of their respective laws in extenuating circumstances, there may be a need to work pragmatically with faith leaders to find acceptable compromises in cases where suitable treatments or treatment regimens do not exist, for example in the case of pancreatic preparations, which are all porcine in origin (table 1 ).

Stereotyping must however be avoided. Arguably, even more important than knowledge of the main tenets of different faiths and access to information about the constituents of medicines then, is that prescribers have the skills and attitudes to explore patients' own beliefs and preferences during prescribing consultations. Parents and children are not passive recipients of prescribing decisions; they have their own views which are a key influence on whether and how they take medications and these must be respected.

A R Gatrad

Manor Hospital and Birmingham University, UK

G Mynors

Medicines Partnership, London, UK

P Hunt

National Patient Safety Agency, London, UK

A Sheikh

Division of Community Health Sciences: GP Section, University of Edinburgh, Edinburgh, UK

Correspondence to: Dr A R Gatrad, Manor Hospital, Moat Road, Walsall WS2 9PS, UK; sec.gatrad@ walsallhospitals.nhs.uk

Competing interests: ARG and AS have (voluntary) positions with the Research and Documentation Committee of Muslim Council of Britain. They, together with GM, were involved in the production of Informed choice in medicine taking: drugs of porcine origin and clinical alternatives which was supported by an unrestricted educational grant from SanofiSynthelabo. Lord Hunt is Chairman of the National Patient Safety Agency.

\section{References}

1 Department of Health. Building on the best: choice, responsiveness and equity in the NHS. London: DoH, 2003.

2 Anon. Family care and medical management for Jehovah's Witnesses. Watch Tower. Brooklyn, NY: Watch Tower Bible and Tract Society, 1995:4-5.

3 Spitzer J. Caring for Jewish patients. Oxford: Radcliffe, 2003.

4 Sattar SP, Shakeel AM, Majeed F, et al. Inert medication ingredients causing non adherence due to religious beliefs. Ann Pharmacother 2004;38:621-4.

\section{Lessons from an unsuccessful local attempt to tackle childhood overweight and obesity}

While we greatly enjoyed Mary C J Rudolph's "Best Practice" article on "The Obese Child", we cannot agree with her conclusion that obesity fulfils most of the criteria for a condition that justifies screening. Our own local experience in Solihull, West Midlands, might illustrate this point.

Using a grant from the Children's Fund (www.cypu.gov.uk/corporate/childrenstrust/ index,cfm) we aimed to set up a "Fit Club" serving children aged $7-11$ in seven wards in Solihull, with DETRI deprivation indices ranging from 7.53 to 54.49 . All seven wards contain enumeration districts with deprivation indices in the worse $15 \%$ of the country.

We attempted to recruit 20 children, for an initial consultation phase, in which they and their families would be able to discuss with our multidisciplinary team the kinds of services they would like to tackle the child's weight. They would be able to try out various exercise programmes if they wished, as well as receiving dietetic advice, and as an incentive we also offered $£ 10.00$ worth of fresh fruit and vegetables. The only criterion for recruitment was that the child should be perceived to have a weight problem both by their family and professionals.

We attempted to recruit children via contact with school nurses, recommendation from general practitioners, and an advertisement in the local paper. To our disappointment, we found that we were able to recruit only four children. GPs had forwarded seven names, of whom one actually made contact with the service, while the school nurses informally fed back that families felt that their child's weight was not an issue on which they needed to take action. A final attempt at recruitment, based on one large primary school with support of teaching staff, was similarly completely unsuccessful. It would seem likely that a difference in perception of the seriousness of overweight and the need for action between parents and professionals explained our disappointing outcomes. $^{2}$

Our experience thus leads us to believe that detecting obese or overweight children by screening will not substantially alter the scale of these problems on a population basis, although services for those that do request them are clearly justified.

N Haisman, K A Matyka, A Stanton Solihull Primary Care Trust, West Midlands, UK; haismann@hotmail.com

\section{References}

1 Rudolph MCJ. The obese child. Arch Dis Child Educ Pract Ed 2004;89:ep57-62.

2 Jeffery AN, Voss LD, Metcalf BS, et al. Parents' awareness of overweight in themselves and their child: cross sectional study within a cohort (EarlyBird21). BMJ 2005;330:23-4.

\section{Author's reply}

Drs Haisman, Matyka, and Stanton describe their disappointing and frustrating experience of offering a programme for obese children. However this experience cannot be used to argue that screening would have no value.

My comment that obesity fulfils most of the criteria for screening was based on the fact that: it is a common condition with serious consequences; it can be identified in its early stages; and it is potentially reversible. If it was reversed the costs of identifying obese children would be more than offset by the savings in health care later. The big "but" is the one (and very major) problem that we cannot offer effective treatment. If we can resolve that, then undoubtedly we should be screening our school age population.

The Solihull experience is not universal. With current sympathetic media interest the climate is changing and we are finding that 
families are seeking help. Our WATCH IT community based programme in Leeds has 65 children enrolled with good attendance and we now have a waiting list.

Rather than dismiss the idea of screening at some point in the future, let us argue for more resources to develop clinically effective interventions.

M C J Rudolf

Department of Community Paediatrics, Belmon House, 3-5 Belmont Grove, Leeds LS17 8DR, UK : mary.rudolf@leedsth.nhs.uk

\section{Patterns and risks in spinal trauma: the emergency transport perspective}

The article by Martin and colleagues ${ }^{1}$ reviewing patterns and risks in spinal trauma highlights the increased incidence of spinal cord injury (SCI) and spinal cord injury without radiological abnormality (SCIWORA) in young children. They suggest that without clinical suspicion proper evaluation of the child's spine may not occur, and refer to an audit by Skellet and colleagues ${ }^{2}$ that shows inadequate spinal immobilisation of paediatric trauma patients on arrival of the paediatric retrieval team.

Preventing secondary injury during transfer (movement of patients between hard surfaces in close proximity) and transport (patient movement between facilities) is particularly important.

There are a number of devices available to facilitate spinal immobilisation during transfer and transport. These include spinal board (SB), vacuum mattress (VM), patslide, and scoop device in combination with traditional hard collar, blocks, and tapes to provide cervical spine immobilisation

We carried out a survey to identify the current practices in immobilisation, transfer, and transport of the paediatric trauma patient with actual or potential SCI. Postal questionnaires were sent to the retrieval coordinators in 18 UK paediatric ICUs asking about methods of spinal immobilisation during transfer and transport of paediatric trauma patients and existence of guidelines for management of that population.

There was a $100 \%$ response rate (postal plus follow up phone calls to two centres). Only $27 \%(5 / 18)$ of retrieval services employed practice guidelines. For patient transfer, $27 \%(5 / 18)$ of retrieval services utilised a patslide device alone and 50\% (9/ 18) utilised a patslide in combination with a vacuum mattress and/or spinal board (table 1). For patient transport, 67\% (12/18) of services had a consistent approach (table 2). A spinal board, either alone or with padding, was used by $72 \%$ (13/18) of services for at least some of their patient transports.

One hundred per cent of services used the traditional triad of hard collar, sandbags/ blocks, and tape/straps for maintaining cervical spine immobilisation.

As Martin et al have described, SCI and SCIWORA occur more frequently in younger children. Without an obvious radiological abnormality, these injuries may potentially be overlooked. Prevention of secondary injury is thus important during transport of at risk patients. Our survey illustrates that there is a lack of a consistent approach to spinal immobilisation during transfer and transport of paediatric trauma patients. There is also continuing use of spinal boards despite
Table 1 Methods of patient transfer $(n=18)$

\begin{tabular}{ll}
\hline & No. \\
\hline Patslide alone & 5 \\
Patslide + VM & 1 \\
Patslide + SB & 4 \\
Patslide + VM or SB & 4 \\
Scoop + SB & 2 \\
VM alone & 1 \\
SB alone & 1 \\
\hline
\end{tabular}

Table 2 Methods of patient transport in services with a consistent approach $(n=12)$

\begin{tabular}{ll}
\hline & No. \\
\hline VM alone & 4 \\
VM + SB & 1 \\
SB alone & 2 \\
SB + padding & 4 \\
Trolley only & 1 \\
\hline
\end{tabular}

evidence that they should only play a role during extrication of patients in the prehospital setting ${ }^{3}$ and that vacuum mattresses may confer benefits in terms of patient safety and comfort. ${ }^{4}$

The development of best practice guidelines may lead to a more consistent approach.

S A Russ, S W Hancock, M Quinton, R Moore Sheffield Children's Hospital, UK

$P$ Harrison

Princess Royal Spinal Injuries Unit, Sheffield, UK

Correspondence to: Dr S W Hancock, Consultant Paediatric Intensivist, Sheffield Children's Hospital Paediatric Intensivist, Sheptield Children's Hospital
Retrieval Service, UK; stephen.hancock@sch.nhs.uk

$$
\text { doi: 10.1136/adc. } 2005.072546
$$

Competing interests: none declared

\section{References}

1 Martin BW, Dykes E, Lecky FE. Patterns and risks in spinal trauma. Arch Dis Child 2004;89:860-5.

2 Skellet S, Tibby SM, Durwood A, et al. Immobilisation of the spinal cord in children. BMJ 2002;324:591-3.

3 Chan D, Goldberg R, Tascone A, et al. The effect of spinal immobilisation on healthy volunteers. Ann Emerg Med 1994;23:48-51.

4 Luscome MD, Williams JL. Comparison of a long spinal board and vacuum mattress for spinal immobilisation. Emerg Med J 2003;20:476-8.

\section{Dapsone therapy for Henoch-} Schönlein purpura: a case series

Henoch-Schönlein purpura (HSP), first recognised by Heberden in 1801, is a systemic, IgA mediated vasculitis of small vessels that is usually self-limiting but may progress to gastrointestinal bleeding, intussusception, and nephropathy. A third of patients will experience recurrences. ${ }^{1}$ Currently treatment is confined to rest, analgesia, and steroids for refractory abdominal pain, ${ }^{2}$ and immunosuppressants for complications, especially renal disease.
Original reports, predominantly in adults, show that the symptoms of purpuric rash, abdominal pain, and arthritis in HSP respond to treatment with dapsone. ${ }^{3-5}$

Even though the first case of HSP treated with dapsone was reported in 1983, it is still not generally recognised as a treatment for HSP. We describe eight children in whom, because of the severity or persistence of their symptoms, treatment with dapsone was commenced from among 41 patients diagnosed with HSP from January 1992 to May 2004. All gained a clinical response from treatment with the most beneficial effect on the skin rash. The demographic characteristics of the patients and their presenting clinical features as well as treatment are shown in table 1 . The rash improved within 3 days to 1 week of starting treatment with dapsone in all patients. Six of eight relapsed when treatment was stopped, but responded again to treatment. The side effects are dose related and uncommon at doses commonly used ( $1-2 \mathrm{mg} / \mathrm{kg}$ daily).

Dapsone, an antileprotic drug, used for a variety of dermatological conditions, appears to be of special value in diseases characterised by accumulation of neutrophils, notably with leucocytoclastic vasculitis, of which HSP is an example. There is evidence that it has antioxidant scavenger effects and may suppress the generation of toxic free radicals in neutrophils. It also inhibits prostaglandin D2 production and synthesis of $\operatorname{IgG}$ and $\operatorname{IgA}$ antibodies. ${ }^{6}$ It may also inhibit IgA-neutrophil interactions. ${ }^{3}$ Given the pathogenesis of HSP with IgA mediated vasculitis, treatment with dapsone represents an exciting form of treatment. The clinical course of our patients suggests that dapsone controls the cutaneous vasculitis rather than cures it. As steroids may mask the features of more ominous intestinal disease, dapsone can be a reasonable alternative. Nonetheless, to date there is no evidence of a positive effect on renal disease.

In conclusion, dapsone is a drug that may have a role in the treatment of HSP. In order to establish its usefulness it is necessary to conduct a multicentre, placebo, randomised controlled trial.

Informed consent was obtained from parents before starting treatment with dapsone.

H lqbal, A Evans Queen Elizabeth Hospital, London, UK

Correspondence to: $\mathrm{Dr} \mathrm{H}$ lqbal, Department of Paediatrics, Queen Elizabeth Hospital, Stadium Road, Woolwich, London SE18 4QH, UK; humai@tiscali.co.uk

doi: $10.1136 /$ adc. 2004.061598

Competing interests: none declared

\section{References}

1 Saulsbury FT. Henoch-Schönlein purpura in children. Report of 100 patients and review of the literature. Medicine 1999;78:395-409.

2 Rosenblum ND, Winter HS. Steroid effects on the course of abdominal pain in children with Henoch-Schönlein purpura. Pediatrics 1987;79:1018-21.

3 Ledermann JA, Hoffbrand BI. Dapsone in allergic vasculitis: its use in Henoch-Schönlein disease following vaccination. J $R$ Soc Med 1983;76:613-14.

4 Sarma PSA. Dapsone in Henoch-Schönlein purpura. Postgrad Med J 1994;70:464-5.

5 Ramelli GP, Bianchetti MG. Dapsone in cutaneous Henoch-Schönlein syndrome-worth a trial. Acta Paediatr 1997;86:337. 
Table 1 Demographic characteristics, presenting clinical feature, and treatment of the patients

\begin{tabular}{|c|c|c|c|c|c|c|c|c|}
\hline & \multicolumn{8}{|l|}{ Patient } \\
\hline & 1 & 2 & 3 & 4 & 5 & 6 & 7 & 8 \\
\hline Age at presentation & $22 \mathrm{~m}$ & $8 y$ & $8 y$ & $51 / 2 y$ & $10 y$ & $5 y$ & $8 y$ & $10 y$ \\
\hline Sex & $\mathrm{F}$ & $F^{\prime}$ & $F^{\prime}$ & M & $\mathrm{F}$ & $F^{\prime}$ & $M^{\prime}$ & $\mathrm{F}$ \\
\hline Race & White & White & White & White & White & White & Vietnamese & White \\
\hline \multicolumn{9}{|l|}{ Presenting features } \\
\hline Miserable & + & - & - & - & - & - & - & - \\
\hline Rash & + & + & + & + & + & + & + & + \\
\hline Joint pain & - & + & + & - & + & + & - & + \\
\hline Joint swelling & + & - & + & - & + & + & - & - \\
\hline Abdominal pain & - & - & + & + & - & + & + & - \\
\hline Vomiting & - & - & - & + & - & + & + & - \\
\hline Swollen testicle & - & - & - & + & - & - & - & - \\
\hline Haematuria & - & + & + & - & + & - & + & + \\
\hline Proteinuria & - & + & + & - & - & + & + & - \\
\hline Rectal bleeding & - & + & - & - & + & - & - & + \\
\hline Length of presentation & $1 d$ & $2 d$ & $2 d$ & $1 d$ & $5 \mathrm{~d}$ & $4 \mathrm{~d}$ & $5 d$ & $1 d$ \\
\hline $\begin{array}{l}\text { Presentation to } \\
\text { treatment }\end{array}$ & $10 d$ & $14 \mathrm{~m}$ & $4 \mathrm{~m}$ & $18 \mathrm{~m}$ & $5 d$ & $8 d$ & $11 \mathrm{~d}$ & $1 \mathrm{~m}$ \\
\hline Dose & $1 \mathrm{mg} / \mathrm{kg}$ od & $1.3 \mathrm{mg} / \mathrm{kg}$ od & $1 \mathrm{mg} / \mathrm{kg}$ od & $1.25 \mathrm{mg} / \mathrm{kg}$ od & $0.75 \mathrm{mg} / \mathrm{kg} \mathrm{bd}$ & $1 \mathrm{mg} / \mathrm{kg}$ od & $1 \mathrm{mg} / \mathrm{kg}$ od & $0.5 \mathrm{mg} / \mathrm{kg} \mathrm{bd}$ \\
\hline Length of first course & $6 d$ & $7 d$ & $4 d$ & $4 w$ & $10 d$ & $7 \mathrm{~d}$ & $14 \mathrm{~d}$ & $10 \mathrm{~d}$ \\
\hline Positive response & Yes & Yes & Yes & Yes & Yes & Yes & Yes & Yes \\
\hline $\begin{array}{l}\text { Relapse after first } \\
\text { course }\end{array}$ & No & Yes & No & Yes & Yes & Yes & Yes & Yes \\
\hline $\begin{array}{l}\text { Total duration of } \\
\text { treatment }\end{array}$ & $6 d$ & $7 d$ & $4 d$ & $21 / 2 y$ & $8 \mathrm{~m}$ & $5 w$ & $5 w$ & $2 y$ \\
\hline
\end{tabular}

6 Thuong-Nguyen V, Kadunce K, Hendrix JD, et al. Inhibition of neutrophil adherence to antibody by dapsone: a possible therapeutic mechanism of dapsone in the treatment of $\lg A$ dermatoses. $J$ Invest Dermatol 1993;100:349-55.

\section{If community paediatricians did not exist, it would be necessary to invent them}

Since 1991 there has been talk of abolishing community paediatrics as a specialty. ${ }^{1}$ At that time, a group of related specialties was proposed: a specialty of child development and rehabilitation (neurodisability); child protection would be subsumed into general paediatrics and there would be child public health doctors. Since then there has been a view among some paediatricians that community paediatricians should become the general paediatricians of the future. ${ }^{23} \mathrm{Dr}$ Chambers' recent article proposes a narrow view of community paediatrics, concentrating on chronic illness and confining its role to diagnosis and medical management. ${ }^{4} \mathrm{He}$ rather misses the point.

\section{The challenge of community paediatrics}

Children do not come in neat packages, with diagnostic labels. They and their families need all their needs met. Hospital practice traditionally concentrates on the illness, not the patient, although this is becoming less with time and paediatricians have always been more holistic than adult counterparts. Hospital practice often deals with complex problems by having specialists for each problem. Our adult physician colleagues are beginning to realise that doesn't work and are reinventing the general physician.

It has been shown that community paediatric patients have significantly more complex problems than those presenting to general paediatricians. ${ }^{5}$ Many of the conditions we diagnose and treat have no diagnostic tests. Community paediatricians need excellent clinical skills, must be able to manage complexity and uncertainty, and must have the ability to communicate across disciplines and across agencies, creating understanding in those who come from different backgrounds and with different agendas. It is not an easy job.

\section{The National Service Framework}

The NSF was constructed by multidisciplinary groups including parents. It is therefore no accident that child health, not illness, is emphasised. Hospital practice has rather less emphasis than crosscutting "out of hospital" issues. Communication, coordination, and early intervention are all key themes. Parents and our sister agencies value medical input that is holistic, available where it is needed (not just in the clinic), and attuned to the needs of the child and family in the community. They demand more of it than we can currently give. Nevertheless, child health outside hospital has moved up the agenda and it will be hard for local authorities to deliver Every Child Matters without focused child health support to education, social, and voluntary services, as well as child health per se. This new agenda requires exactly the skills community paediatricians have. If community paediatricians did not exist, it would be necessary to invent them to deliver the NSF. The challenge is how we tackle it.

Dr C M Ni Bhrolchain Consultant Community Paediatrician, Wirral Hospital NHS Trust, UK; cliona_nib@lineone.net

Competing interests: Dr Ni Bhrolchain in a Specialty Training Advisor in Community Child Health. These views are her own.

\section{References}

1 Hall DMB. Do we really need community paediatricians? A summary of the lecture given to the Triennial Meeting of the Scottish Paediatric Society. Eur J Pediatr 1991;150:530-1.

2 Chambers TL. Death of the general paediatrician? Arch Dis Child 1997;77:364-7.

3 Royal College of Paediatrics and Child Health. The next ten years. Educating paediatricians for the new roles in the 21 st century. London: $\mathrm{RCPCH}$, 2002

4 Chambers TL. An open letter to Doctors Mather and Bannon. Arch Dis Child 2005;90:236-7.

5 Holmes N, Ni Bhrolchain CM. Case mix presenting to paediatricians in a UK district (1998). Public Health 2002; 116:179-83.

\section{Melatonin: a panacea for desperate parents? (Hype or truth)}

Sleep disorders are common in children with neurodevelopmental disorder and are a major source of stress for the whole family. In children with neurodevelopmental disabilities the prevalence may be as high as $80 \%{ }^{.}$ The current literature is suggestive of circadian rhythm dysfunction, social difficulties, and abnormal melatonin levels in children with autism. ${ }^{2}$

Hypnotics and sedatives can produce side effects and tolerance, ${ }^{3}$ so is melatonin the answer in children with sleep problems associated with severe developmental difficulties of social and communicating nature, which have not responded to behavioural and social measure? Previous studies and case reports have suggested that melatonin could be effective.

We retrospectively reviewed cases of nine autistic children with chronic sleep disorder, who were attending the Child Developmental Centre at Windmill Lodge. The age range of these children was $2-11$ years. No additional non-pharmacological sleep intervention was instituted. They were started on $2.5-5 \mathrm{mg}$ melatonin 45 minutes before their sleeping time. In four of these patients sleep latency was reduced. Our own experience of reduction in sleep latency is in accordance with literature. ${ }^{4}$ Five parents reported improvement in total duration of sleep. In 
three patients medication was stopped within a week because of no response. Four patients are still on melatonin for over a year without any side effects. We could not find the cause in non-responders.

To find out the real benefit of melatonin, the dose, short and long term side effects, and group of patients who will respond to melatonin, several authors have already identified the need for a double blind crossover study. ${ }^{4}$ Previous studies have reported response rates of up to $80 \%,{ }^{5}{ }^{6}$ but it is seems likely that studies which group together children with "neurodevelopmental disorders" in a generic manner will not furnish the answer as to the true place of melatonin in the management of disturbed sleep patterns.

R Gupta

Ealing Hospital NHS Trust, London, UK

J Hutchins

Ealing PCT, London, UK

Correspondence to: Dr R Gupta, Department of Paediatrics, Ealing Hospital NHS Trust, Uxbridge Road, Southall, London UB1 3EU, UK reeta_pradeep@yahoo.com

Competing interests: none declared

\section{References}

1 Bartlett LB, Rooney V, Spedding S. Nocturnal difficulties in a population of mentally handicapped children. Br J Ment Subnorm 1985;31:54-9

2 Patzold LM, Richdale AL, Tonge BJ. An investigation into sleep characteristics of children with autism and Asperger's disorder. J Paediatr Child Health 1998;34:528-33.

3 Hung JCC, Appleton RE, Nunn AJ, et al. The use of melatonin in the treatment of sleep disturbances in children with neurological or behavioural disorders. J Pediatr Pharm Prac 1998;3:250-6.

4 Phillips L, Appleton RE. Systematic review of melatonin treatment in children with neurodevelopmental disabilities and sleep impairment. Dev Med Child Neurol 2004;46:771-5

5 JanJE, O'Donnell ME. Use of melatonin in the treatment of paediatric sleep disorders. Journal of Pineal Research 1996;21:193-9.

6 Jan JE, Espezel H, Goulden KJ. Melatonin in sleep disorders of children with neurodevelopmental disabilities. In: Shafii M, Shafii SL, eds. Melatonin in psychiatric and neoplastic disorders. Progress in Psychiatry No. 55, 1998.

\section{An integrated care pathway for looked after children can facilitate multi-agency coordination}

Looked after children are a vulnerable population at risk of unidentified and unmet health needs. Coordinated input from health, social care, and education services for these children is required by government but is not easily achieved.

The focus on looked after children has sharpened with the Quality Protects programme, a major initiative launched in 1998 to improve their life chances. In 2002, the Department of Health (DH) published guidance on how to develop a health service for looked after children. ${ }^{1}$

"Children in special circumstances", including looked after children, are prominent in the National Service Framework (NSF) for Children Young People and Maternity Services. Implementation of the DH guidance is explicitly required by the NSF.
The Children Act 2004 sets out a new framework for children's services with Directors of Children's Service and Lead Members for children in each local authority. ${ }^{2}$ The government is establishing Children's Trusts to drive the coordination and integration of planning, commissioning, and delivery of health, social care, and education services

How are these agencies to work together more effectively? There are well recognised facilitators and barriers to coordinating multi-agency practice. ${ }^{3}$ Poor communication between agencies and a lack of understanding of each other's roles and responsibilities has been a barrier and is a recurring feature in reports of child abuse and child deaths.

An integrated care pathway (ICP) is a health sector concept that "determines locally agreed multidisciplinary practice based on guidelines and evidence, where available, for a specific patient user group. It forms all or part of the clinical record, documents the care given and facilitates the evaluation of outcomes for continuous quality improvement".4 The ICP concept is multifaceted and complex but consists of both a process (of development and continuing maintenance) and a set of operational products. It can usefully be extended as a tool to improve multi-agency working.

An ICP to promote the health of looked after children has been developed in Birmingham. The products include a process map, updated health assessment documentation, and a variance reporting strategy. ${ }^{5}$

At its best an ICP can be a mechanism to enhance collaborative working across agencies for specific populations such as looked after children.

D Simkiss

Division of Health in the Community, Warwick Medical School, Coventry CV4 7AL, UK d.e.simkiss@warwick.ac.uk

doi: 10.1136/adc.2005.072645

Competing interests: none declared

\section{References}

1 Department of Health. Promoting the health of looked after children. London: Department of Health, 2002

2 www.legislation.hmso.gov.uk/acts/acts2004/ 20040031.htm (accessed 10 January 2005).

3 P Sloper. Facilitators and barriers for coordinated multi-agency services. Child Care Health Dev 2004:30:571-80.

4 de Luc K. Developing care pathways: the handbook, Radcliffe Medical Press, 2001

5 Birmingham City Council Social Care and Health. A care pathway for the health of looked after children in Birmingham, Birmingham City Council Social Care and Health, 2004.

\section{BOOK REVIEWS}

\section{Spotting the sick child (DVD)}

Edited by Ffion Davies. University Hospital of Leicester and Royal College of Paediatrics \& Child Health, 2004, £8.99 single copy, or $£ 6.46$ for orders of six or more. ISBN 1904039111

This innovative joint project between the Department of Health and the Royal Colleges of Accident and Emergency Medicine and Paediatrics and Child Health is an extremely useful educational resource. The DVD was commissioned due to the concern of the Department of Health in England about door-to-needle times for meningococcal disease in children. The aim was to set up a video teaching package for A\&E doctors and paediatricians about recognition of serious illness in childhood. The original remit was extended to include GPs, paramedics, emergency care practitioners, and others assessing children. I noticed that all the consultants received a copy as part of the Children's National Service Framework package and it looked interesting. The cartoon representations on the cover artwork show a worried-looking doctor bemused by caricatures of spotty, crying, febrile, and flushed children. This simple and inviting imagery nicely reflects the subject matter.

The DVD uses an interface which will be familiar to most. Seven menus, covering the top presenting emergency symptoms in childhood, function as gateways to symptoms based tutorials. This simple menu system is useful to get to a particular section quickly. But there is no opportunity to interact with clinical material or cases, or for making management decisions.

The opening sequence contains many of the images we will see during the DVD set to a symphony of crying, coughing, and calming background banter from parents, nurses, and doctors. It might put off healthcare professionals who are not used to this sort of decorum in a paediatric A\&E, but it is a cute way to introduce the content. Following this there is a head-to-head edited interview with a "TV doc" and an A\&E consultant (you can skip the entire intro at the push of a button). The conversation makes interesting watching as the TV doc tries to justify why spotting a sick child is so important. The A\&E consultant gives a far more grounded perspective to assessing children in the clinical setting. The TV doc suggests there is a culture of practicing defensive medicine, but the A\&E consultant (much more the voice of reason) declares it is more to do with human nature that we try our best to spot the sick child and not miss something important. Surely safe medicine is defensible and that should be the focus.

There are many great video clips shown, often with explanatory narrative and some with a visual caption. Being involved in a similar project locally to capture video of acute presentations and clinical signs for teaching I can appreciate the time and effort put into obtaining useable footage as well as the goodwill of patients and their parents. Some of the clips within each section are repeated-the same breathless baby, croupy cough, or miserable infant. But that is reinforcement and a useful educational tool. The "red flags" are particularly helpful, although some are no more than a "talking head" explaining a worrying symptom or making a learning point without any video or visual aid to back up or reinforce the point. It is worth mentioning that along with excellent footage of symptoms, signs, and clinical evaluation is a lot of talk. The team of presenters use a formal and didactic delivery style, assiduously reading their script from an autocue. The tone is serious which is appropriate for the topic material, but paediatrics can be a fun and up-beat speciality. Most sick children do get better!

I liked the 3 minute toolkit showing how an examination can be completed with the child on the mother's knee. I always think is nice to ask younger children if I can examine them 
but am in trouble if they defiantly say "no!". I did not find any tips to deal with children who are difficult to examine. One highlight among the many excellent clips showing physical signs was the examination of the child with peritonitis. He winces and holds his abdomen rigid, even pushing the examining hand away. Watching such an examination is then next best thing to examining the child yourself, certainly better than a didactic session on clinical examination.

This DVD is a powerful, versatile, and informative resource which will be able to offer many healthcare professionals in all specialties and at all levels of training insight into how an ill child might look in practice. This is most useful in current times with the usual arguments over reduced time in training and the reduction in working hours. Anyone would feel more skilled after spending time with this DVD. I hope it will help to demystify the paediatric assessment and give those clinical signs which we strive to explain a real and "live" feel. This DVD, with its instructive and common-sense approach, should take pride of place in induction programmes and would be a valuable teaching resource in any $A \& E$ department, paediatric unit, or GP surgery. Overall it definitely does what it says on the box.

A Reece

\section{Immunization in practice, a practical guide for health staff}

World Health Organisation, 2004, pp 230 $€ 31.13$ (paperback book and CD-ROM). ISBN 9241546514

There have been some great successes in global immunisation in the last decade with the near eradication of polio and reductions in neonatal tetanus. In some developing countries childhood immunisation coverage is increasing, but in others it is still extremely low; for example, only $50 \%$ of infants in SubSaharan Africa compared to the United Nations goal of $90 \%$. There is still great inequality between wealthy and low income countries in access to and delivery of safe vaccination. Thus there are millions of the most vulnerable children at risk of life threatening and disabling diseases.

The challenge of global immunisation

Leaving political and economic problems aside, how can immunisation rates in developing countries be improved and sustained? This book aims to provide a resource of practical and management skills to health workers in developing countries to reach this goal, and could equally be used as a training manual. It is the result of work between many organisations including the WHO, Children's Vaccine Program, and UNICEF. It covers the common target diseases and their vaccines, and aims to promote the use of underused vaccines such as Hib, yellow fever, and hepatitis B. The immunisation schedule is based on the "Expanded Programme on Immunisation" and includes combination vaccines, for example, DTP-HepB + Hib. The book would need to be used in conjunction with up to date national policies and vaccine schedules, which vary between countries and are regularly changing as new vaccines are introduced. The book is divided into eight modules with summary tables to emphasise key points and clear diagrams. It covers the practical aspects of delivering effective immunisation in great detail, for example, the cold chain including details of transport and refrigeration. It explains how to make a homemade sharps container and how to dispose of them, from incineration to burying in a disposal pit. Information on the diseases, vaccines, and side effects is quite brief, but practical.

The module on holding an immunisation session emphasises safe practice to reduce needle stick injuries, including how to set up a clinic, injection techniques, and adopting autodisable syringes to prevent reuse. Strategies are listed to improve coverage by developing a district plan from fixed, outreach, and mobile clinics, estimating vaccine needs, and on building links with the local community. Further modules cover the monitoring and recording of data.

This book is designed for developing countries and would be less useful for health professionals in the UK. It does not cover many of the new vaccines used in the UK, for example, conjugated pneumococcal or meningococcal vaccines, which are not priorities in developing countries. However, the practical sections on holding an immunisation session set clear quality standards which should be adopted by any organisation delivering an immunisation clinic. Up to date information on the UK immunisation schedule can be found online in the "Green Book" and its updates at http://www.immunisation.nhs.uk/ under the publications section. The full version of this book can be found online at http://www.who.int/vaccines-documents/DoxTrng/h4iip.htm. Overall this book will be a valuable tool in the global challenge of delivering safe and effective immunisation to all children.

A Isaacs

\section{Key topics in neonatology, 2nd edition}

Edited by Richard H Mupanemunda, Michael Watkinson. London: Taylor \& Francis, 2005 $£ 28.95$, pp 420. ISBN 1859962343

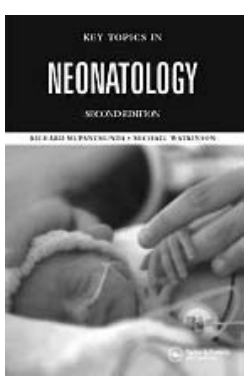

The second edition of Key topics in neonatology claims to provide a quick and very up to date summary of current concepts in neonatology, in a self contained and easily readable problem based format for neonatal trainees and nurses. The authors recommend the text as an ideal revision aid for MRCPCH and DCH candidates. The book is very compact and has just over 400 pages, with common neonatal problems arranged alphabetically, which we found easy to use.

The authors do acknowledge that some topics reflect their personal practice; however each topic ends with a useful reading list and related topics of interest, which encompasses other contemporary views. References to family support groups are also helpful.

The majority of sections give good, clear, concise advice and certainly fulfil the role of a revision text. However, we would like to have seen cardiac tamponade included as a cause, in the section on acute neonatal collapse, and the use of echocardiography in the list of investigations to exclude this. The session on ambiguous genitalia was weak, mainly because of the incorrect premise that $90 \%$ of cases are females with congenital adrenal hyperplasia. The authors have decided to cling on to outmoded terms such as "nesidioblastosis" and "hermophrodite", and the "Papile" classification given for grading of intracranial haemorrhage.

Because of the problem based format, some topics were necessarily repeated, and there were some inconsistencies in recommendations in different sections of the book. For example, hepatitis B immunoglobulin is recommended to be given within 24 hours in one section and within 48 hours in another. The normal anion gap is given as 6-14 in one place and as 8-16 in another. Inconsistencies were also noted in cord haemoglobin and bilirubin values for recommended early exchange transfusion.

There was an excellent "special notes" section with a discussion of the appropriateness of different types of volume replacement and inotropes in hypotension. We would have liked to see similar sections surrounding some other controversial subjects and management issues. Despite suggesting that saline should be the usual fluid of choice, it appears that the authors' practice is to use blood products in their clinical management, in other areas of the text.

We decided to do a test run using the book to see if it matched up with the authors' claims that it is a quick reference book in the neonatal unit, by referring to the book, to guide us in management on a few admissions to the neonatal unit.

The first clinical scenario was a baby whose mother was diagnosed with maternal HIV after delivery. In less than a minute we had detailed information on perinatal HIV management along with web addresses of useful links-impressive indeed! Unfortunately in the five page chapter on HIV, only half a page was dedicated to neonatal prophylaxis. There is no mention about the ethical and legal issues when a mother refuses antenatal or postnatal HIV testing. The text did not help in the management of the baby in this case; however the cited excellent website of "Bhiva" came to the rescue in deciding what precise treatment need to be given.

The second scenario was a baby with pulmonary hypertension where we wanted check formulas for oxygenation index and AaDO2. Again within seconds, everything was in front of us. Although we wanted to check the length to which umbilical arterial catheter should be inserted for this baby, we were disappointed as there was no mention of a formula anywhere.

The third scenario was the counselling of a mother with antenatally diagnosed ventriculomegaly in the fetus. Unfortunately this was not mentioned anywhere in the book. However, there was very detailed information on the "Epicure study" and neurodevelopmental outcome of babies born at extremes of viability. This will be very handy information for neonatal registrars in counselling expectant mothers in preterm labour.

The final scenario for the test run was to ascertain the investigation and drug therapy for an 8 week old premature baby with conjugated jaundice. The topic is described in great detail under both jaundice and liver disorders, and there is a huge list of causes of neonatal hepatitis. Inclusion of conditions such as erythrophagocytic 
lymphohistiocytosis and ARC syndrome made us acutely aware that the book is from Birmingham!

In summary, this book would be a useful edition to neonatal units as a rapid reference guide, particularly for the excellent web links. The layout of the book is very practical and in a problem oriented style. The lists given under "aetiology" of most conditions are extensive and theoretical, but will be a helpful revision aid for junior doctors and nurses.

S Thayyil, A L Ogilvy-Stuart

\section{Prevention of allergy and allergic asthma: World Allergy Organization project report and guidelines}

Edited by S G O Johnsson, T Haahtela. Karger, 2004, €127.00 (hardback), pp 211. ISBN 3 805578105

Edited by two Scandinavian experts in the field, this book is the result of a working group of the World Allergy Organization (WAO) and the WHO. With contributions by authors from 21 countries it presents a contemporary international overview and consensus of what is known and not known about prevention (primary, secondary, and tertiary) of allergic disorders.

The introduction includes clear definitions of some terms such as allergy and hypersensitivity. It also sets out the useful instruction to all the authors to include an evidence base category with all references-and this book cannot be criticised for a lack of references!

The genetics of allergy are then reviewed in detail that is moderately technical but highlights some of the problems with the results from research to date, such as the varying definitions of atopy (that is, phenotype definition) used in different studies. Despite much effort and the advance of molecular biology, there are still few new certainties about the inheritance of allergy, but strategies for future work are described.
Unsurprisingly, the longest chapter in the book analyses proposed environmental influences causing asthma and allergy. Various dietary factors from fish oils to food additives are discussed. Topical issues such as the hygiene hypothesis, the influence of immunisations, antibiotics, and probiotics (live microbial food components) are all examined and the data presented concisely. What is known about the benefits of breast feeding and weaning is also summarised. The clearest conclusion is that environmental tobacco smoke is bad for allergic airways disease and more governmental action is required.

Another chapter reviews the fascinating issue of immunological influences on the fetus and neonate, showing that significant immune responses occur in utero, influenced by passage of allergen from mother to fetus.

Subsequently, the interventions in infants at high risk of developing allergy are concisely analysed with regard to altering maternal diet during pregnancy and lactation and reducing household aeroallergens. Of clinical relevance is the conclusion that there is no evidence of a preventative benefit of soy based compared with cows' milk formulae.

"Can I do anything to stop my child getting asthma and/or eczema" is a concern of an increasing number of parents. Paediatricians, who are often faced with this question, do not have easy access to specialist allergy opinion at present, because allergy as a medical specialty in the UK could itself be considered to suffer from "failure to thrive". Any paediatrician or clinician with an interest in asthma, eczema, or food allergy (are there any who don't?) will find this book helpful. For anyone drafting local ward and/or community guidelines for nutrition, weaning, and allergy, it provides an evidence base and also some suggested information sheets and guidelines.

A minor criticism is that the subject index suffers from restricted development.

In conclusion, this book would be a useful resource for those interested in allergy within specialist departments and also for reference to the general paediatrician with an interest.

I Pollock

\section{Book reviews in Fetal and}

Neonatal edition

The following book reviews are published in this month's Fetal and Neonatal edition:

- Managing newborn problems: a guide for doctors, nurses and midwives

- Neonatal respiratory disorders, $2^{\text {nd }}$ edn

\section{CORRECTION}

doi: 10.1136/adc.2003.032052corr

Kendrick D, Royal S. Cycle helmet ownership and use; a cluster randomised controlled trial in primary school children in deprived areas (Arch Dis Child 2004;89:330-5). There were two errors in the sample size calculation for this article. The correct figures should be 93\% (not $90 \%$ in the calculation for helmet owning) and $48.5 \%$ (not $44.5 \%$ in the calculation for helmet wearing). Therefore, the sample size calculation should read:

The study had $80 \%$ power to detect a difference in the percentage of children owning a helmet from $81 \%$ to $93 \%$ between the 2 treatment groups.

and

It had $80 \%$ power to detect a difference in the percentage of children always wearing a helmet from $34 \%$ to $48.5 \%$, at the $5 \%$ significance level.

\section{Pre-published book reviews}

Book reviews that have been accepted for publication but have not yet been published in the print journal can be viewed online at http://adc.bmijournals.com/misc/bookreviews.shtml 